\title{
Three cases of laparoscopic total gastrectomy with intracorporeal esophagojejunostomy for gastric cancer in remnant stomach
}

\author{
Yu Pan, Yi-Ping Mou*, Ke Chen, Xiao-Wu Xu, Jia-Qin Cai, Di Wu and Yu-Cheng Zhou
}

\begin{abstract}
Gastric cancer in remnant stomach is a rare tumor but with poor prognosis. Compared with conventional open surgery, laparoscopic gastrectomy has potential benefits for these patients due to advantages resulting from its minimally invasive approach. Herein, we report on three patients with gastric cancer in remnant stomach who underwent laparoscopic total gastrectomy with intracorporeal esophagojejunostomy successfully. The operative time was 280, 250 and 225 minutes, the estimated blood loss was 100, 80 and $50 \mathrm{ml}$ and the length of postoperative hospital stay was seven, eight and nine days respectively. Our experience has suggested that laparoscopic total gastrectomy with intracorporeal esophagojejunostomy can be a safe, feasible and promising option for patients with gastric cancer in remnant stomach.
\end{abstract}

Keywords: Laparoscopy, Gastrectomy, Gastric remnant cancer, Intracorporeal anastomosis, Esophagojejunostomy

\section{Background}

Gastric cancer in remnant stomach is categorized as carcinoma arising from the remnant stomach after partial gastrectomy, regardless of the histology of the primary lesion (benign or malignant) or its risk of recurrence [1]. It has a poor prognosis and surgical resection remains the only effective modality of treatment. Most patients cannot withstand the huge blow caused by conventional open surgery because of their poor general condition. Therefore, laparoscopic surgery, well known for its minimally invasive advantages, is likely a preferable choice for these patients. However, the technical difficulty required for the procedure remains the major concern, especially for the safety of laparoscopic adhesiolysis and intracorporeal esophagojejunostomy. Our surgical term introduced the laparoscopic technique on the gastric cancer in remnant stomach successfully in our department based on our experience in the laparoscopic approach for diseases of digestive tract [2-5]. Herein, we report three cases of laparoscopic total gastrectomy with intracorporeal esophagojejunostomy (LTGIE) for gastric

\footnotetext{
*Correspondence: mouyiping2002@163.com Department of General Surgery, Sir Run Run Shaw Hospital, School of Medicine, Zhejiang University, 3 East Qingchun Road, Hangzhou 310016, Zhejiang Province, China
}

\section{Case presentation \\ Case 1}

The patient was a 55-year-old male who underwent a distal gastrectomy with a Billroth II gastrojejunostomy for a peptic ulcer 30 years previously. The patient underwent a gastroscopy because of abdomen discomfort and a mass was found at the lesser curvature of the remnant stomach. A histological examination confirmed adenocarcinoma and a further examination did not reveal any distant metastasis.

The patient's position and the placement of trocars were similar to our previous studies [6]. The harmonic scalpel and scissors (Harmonic Ace scalpel, Ethicon Endo-Surgery, Inc, Cincinnati, $\mathrm{OH}$ ) were used to separate the adhesions between the bowels, liver and abdominal wall (Figure 1). The remaining lesser omentum was dissected, exposing the common hepatic artery, splenic 


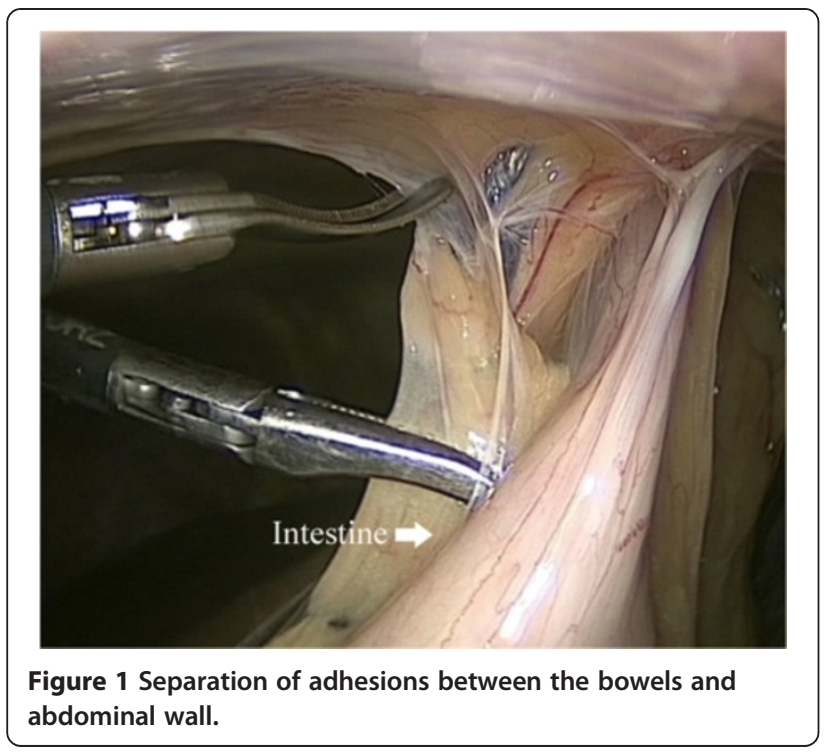

artery and the left gastric artery (Figure 2). The left gastric artery was dissected at the origin. After isolating the gastrointestinal anastomotic site (Figure 3), the input and output jejunal loops were lifted. With endoscopic linear staplers (Endocutter 60 staple; Ethicon EndoSurgery, Inc, Cincinnati, OH), both input and output jejunal loops were transected at a point $5 \mathrm{~cm}$ distal to the anastomotic site. The remaining omentum was isolated to the splenic flexure. The short gastric vessels and the gastrosplenic ligament were dissected, mobilizing the stomach and exposing the esophagus.

An intracorporeal esophagojejunostomy was performed using endoscopic linear staplers. Two small holes were created; one on the anti-mesenteric side of the jejunum and the other on the esophageal stump. Each jaw of the endoscopic linear stapler was inserted into the holes. After

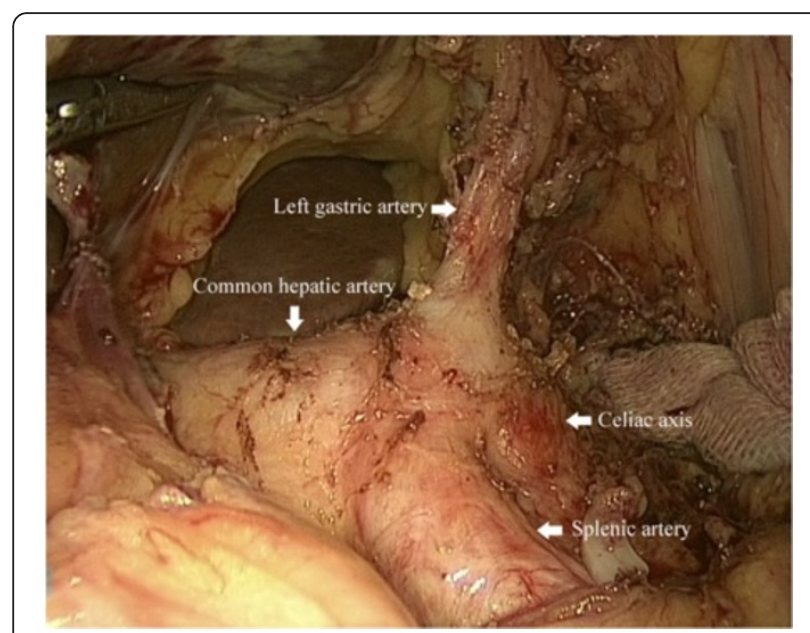

Figure 2 Exposure of the common hepatic artery, splenic artery and the left gastric artery.

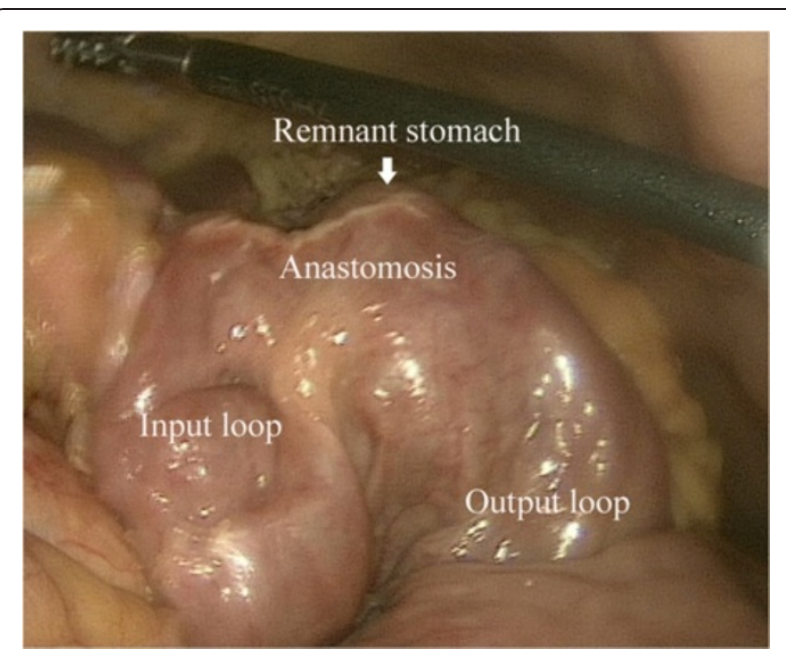

Figure 3 Isolating the gastrointestinal anastomotic site.

stapling, a side-to-side esophagojejunostomy was constructed (Figure 4A). The common opening was closed and the esophagogastric junction was divided using endoscopic linear staplers (Figure 4B). The side-to-side enteroenterostomy to the Roux loop was made about $35 \mathrm{~cm}$ below the esophagojejunal anastomosis using an endoscopic linear stapler. The common opening was closed using the hand-suturing technique.

\section{Case 2}

The patient was a 76-year-old male who underwent radical subtotal gastrectomy with a Roux-en-Y gastrojejunostomy for gastric cancer six years previously. The latest annual review of gastroscopy revealed a lesion in the remnant stomach and a histologically confirmed adenocarcinoma. Preoperative examinations did not show any distant metastasis.

Dividing adhesion and mobilizing the stomach similar to case 1, the remnant stomach was lifted up; a purse-string suture was placed on the esophagus. A hole was made at the esophagogastric junction using a harmonic scalpel. The anvil (ECS 25, Ethicon Endo-Surgery, Inc, Cincinnati, $\mathrm{OH})$ was introduced into the esophageal stump through the hole, then the purse-string suture was tightened (Figure 5A). The esophagogastric junction was divided and the remnant stomach was extracted. The circular stapler was introduced into the jejunum through the jejunal stump, attached with the anvil and fired (Figure 5B). The jejunal stump was closed with endoscopic linear staplers.

\section{Case 3}

A 75-year-old male was admitted for repeated abdominal pain. He underwent a distal gastrectomy with a Billroth II gastrojejunostomy for a peptic ulcer 30 years previously. An adenocarcinoma near the anastomotic site of the stomach was found and a further examination did 

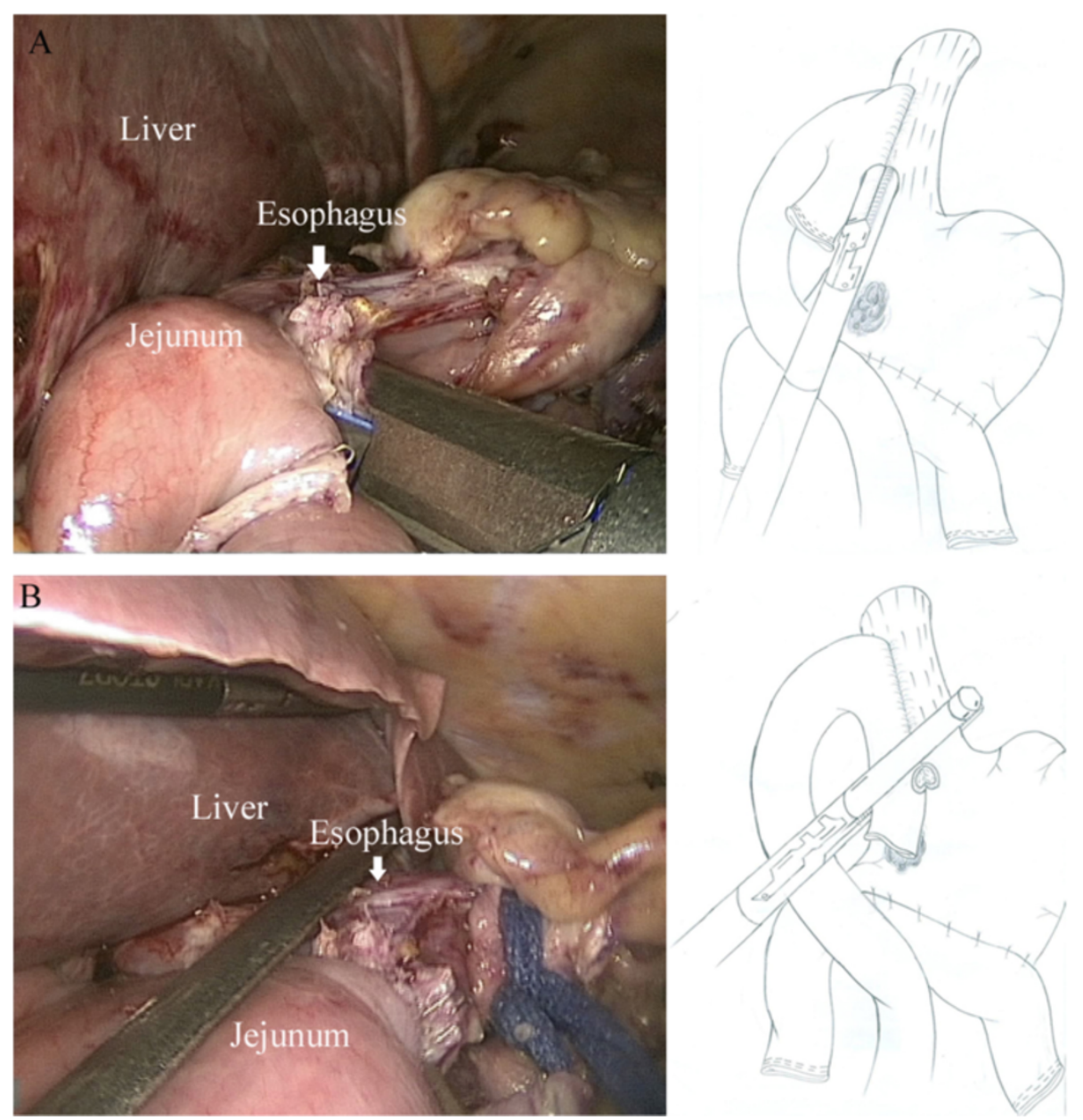

Figure 4 Side-to-side intracorporeal esophagojejunostomy. A. Each jaws of linear stapler is inserted into holes on the esophageal stump and the jejunum, then the linear stapler is fired. $\mathbf{B}$. The common opening is closed using linear stapler.

not find any distant metastasis. The patient underwent the operation as in case 1.

The three patients underwent entirely laparoscopic procedures without conversion. The operative time was 280 , 250 and 225 minutes, the estimated blood loss was 100, 80 and $50 \mathrm{ml}$ and the number of retrieved lymph nodes was 18, 10 and 22, respectively. Their postoperative course was uneventful; the three patients were discharged at postoperative day seven, eight and nine respectively. One patient is alive with no evidence of tumor recurrence. One patient (case 1) suffered tumor recurrence at 14 months after the operation and died at 17 months after the operation. One patient (case 2) died from Alzheimer's 19 months after the operation, with no evidence of tumor recurrence. The clinical characteristics, surgical outcomes and long-term outcomes are shown in Table 1.

\section{Discussion}

The incidence of gastric cancer in remnant stomach is about 3 to $5 \%[7,8]$. Previous reports show gastric cancer in remnant stomach may be associated with the lower acidic environment in the gastric stump, duodenogastric reflux, Helicobacter pylori infection and Billroth II reconstruction $[9,10]$. Gastric cancer in remnant stomach has often been described as having a poor clinical outcome, with five-year survival rates of between 7 and 33\% in previous studies [11,12], and surgery is still the mainstay way to cure. Many patients with gastric cancer in remnant stomach are aged, with denutrition from prior gastrectomy. Thus, it is a great challenge for them to undergo conventional open surgery uneventfully and some patient-friendly procedures, such as laparoscopic procedures, are needed. Laparoscopic procedures for gastric cancer have gradually gained acceptance worldwide, and especially in some East Asian countries it has become the preferably choice due to advantages resulting from its minimally invasive approach $[13,14]$.

However, the technical complexity of the procedure caused by adhesion and the anatomical deterioration has compelled many surgeons to discontinue their trials. Severe intraperitoneal adhesion was previously considered 

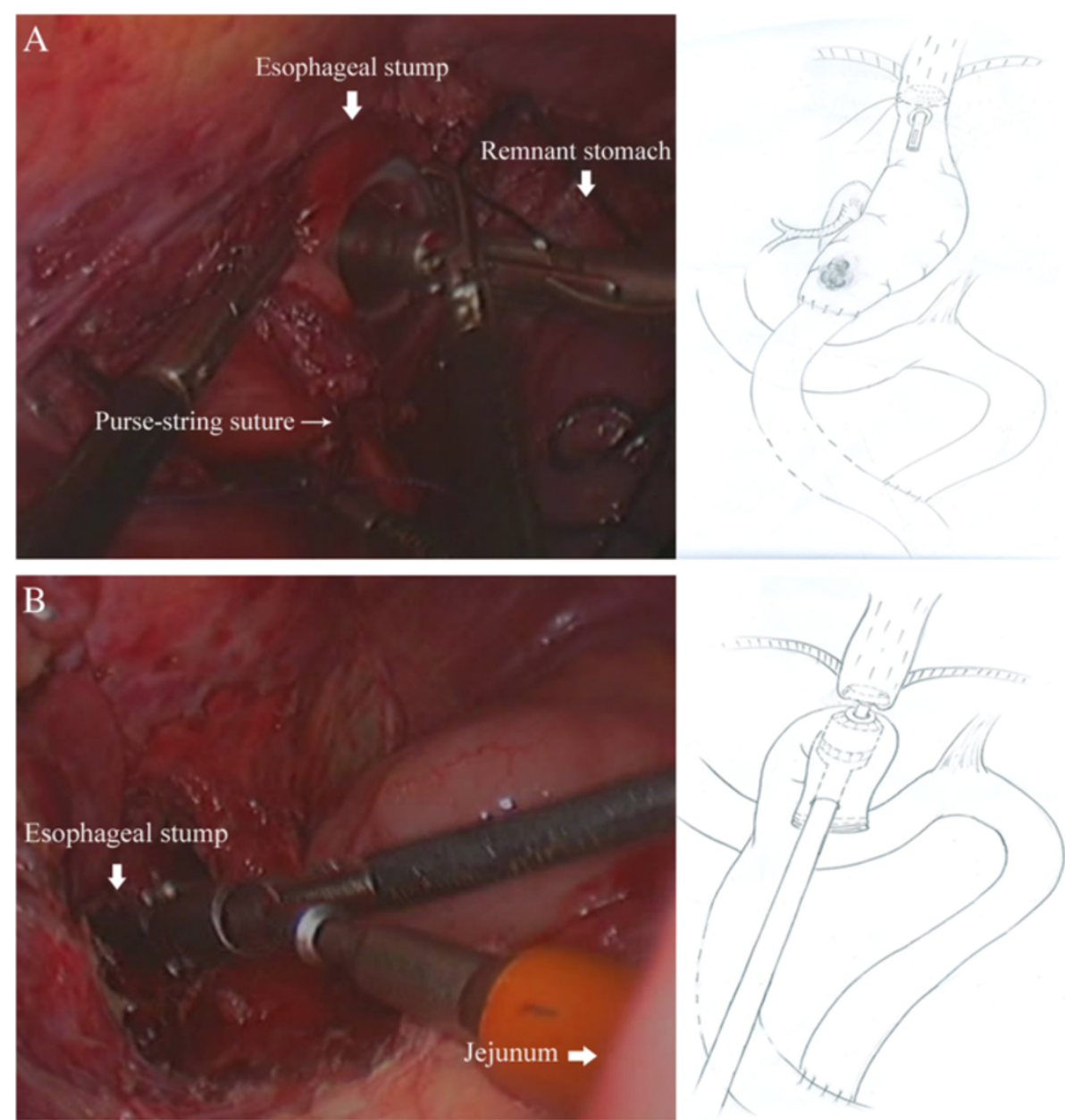

Figure 5 End-to-side intracorporeal esophagojejunostomy. A. The anvil is introduced into the esophageal stump through the hole, then the purse-string suture is tightened. B. The circular stapler is introduced into the jejunum through the jejunal stump, attached with the anvil and fired.

Table 1 Clinical characteristics and outcomes of the three patients

\begin{tabular}{lccc}
\hline & Case $\mathbf{1}$ & Case $\mathbf{2}$ & Case $\mathbf{3}$ \\
\hline Age/sex & $55 / \mathrm{M}$ & $76 / \mathrm{M}$ & $75 / \mathrm{M}$ \\
Previous disease & $\mathrm{PU}$ & $\mathrm{GC}$ & $\mathrm{PU}$ \\
Prior anastomosis & $\mathrm{B}-$ II & $\mathrm{R}-\mathrm{Y}$ & $\mathrm{B}-\mathrm{II}$ \\
Time since prior operation (years) & 30 & 6 & 30 \\
Operation time (minutes) & 280 & 250 & 225 \\
Intraoperative blood loss (mL) & 100 & 80 & 50 \\
Retrieved lymph nodes & 18 & 10 & 22 \\
First flatus (days) & 2 & 3 & 5 \\
Postoperative oral intake (days) & 3 & 4 & 5 \\
Postoperative hospital stay (days) & 7 & 8 & 9 \\
Follow-up period (months) & 17 & 19 & 14 \\
\hline
\end{tabular}

GC, gastric cancer; PU, peptic ulcer; R-Y, Roux-en-Y; B-II, Billroth II. as contraindicative for laparoscopic procedures. With the development of the laparoscopic devices and surgical skill, laparoscopic procedures nowadays are performed in the treatment of postoperative adhesive ileus and incisional hernia $[15,16]$. Thus, it is possible to perform laparoscopic adhesiolysis safely on patients with gastric cancer in remnant stomach. Moreover, the laparoscopic magnified view allows adhesiolysis to be more meticulous than open surgery. We also believe that insertion of the first trocar in the open method can reduce risk of intestinal injury, and great care is needed to avoid injuring the colonic arteries and the colon when separating severe adhesion between mesocolon and jejunum.

To date, a few laparoscopic procedures for gastric cancer in remnant stomach have been reported and most were laparoscopic-assisted gastrectomy (LAG) [17-19]. Kwon et al. reported LAG are technically feasible approaches for the management of remnant gastric cancer for experienced surgeons [20]. However, LAG requires 
mini-laparotomy, which appears to spoil it's minimally invasiveness advantages. Some surgeons have reported that laparoscopic gastrectomy with intracorporeal anastomosis has advantages over LAG, such as better cosmesis, less pain and less intraoperative blood loss [21,22]. Additionally, LAG is not suitable for obese patients or those with a short esophageal stump [23]. Forceful tension and limited vision will cause tearing of the structure near the anastomosis, leading to a higher risk of fistula. Therefore, we chose to perform LTGIE for our patients. In our studies, the patients' postoperative outcomes are consistent with previous studies [24], with a fast recovery and short hospital stay.

The technical difficulty of intracorporeal esophagojejunostomy is another critical obstacle for surgical safety. To overcome this problem, some modified techniques have been reported $[25,26]$. These methods help to simplify the procedure of reconstruction and shorten the operation time. The most representative method is the side-to-side approach using an endoscopic linear staple. With this method, the anastomosis is not dependent on the size of the esophagus or the jejunum, but the endoscopic linear staple. A large anastomosis can be easily achieved, imposing less risk of anastomotic stricture. In our study two cases were successfully performed with this method with no anastomosis-related postoperative complications. Also, one patient had a Roux-en-Y gastrojejunostomy during a prior operation in our study. To preserve the Roux limb as long as possible, considering proper length of the Roux limb to protect the esophagus from entero-esophageal reflux, an end-to-side anastomosis seemed to be the most suitable approach. As a representative technique for intracorporeal end-to-side esophagojejunostomy, the $\mathrm{OrVil}^{\mathrm{mm}}$ (anvil) technique facilitates the conventional intracorporeal anastomosis and is time-saving. However, this technique may bring the risks of oral bacterium infection and injure the esophagus during insertion and it was unavailable in our institution. Thus, we performed the intracorporeal anastomosis with a conventional circular stapler rather than the $\mathrm{OrVi}^{\mathrm{lit}}$ technique.

\section{Conclusions}

LTGIE can be a safe, feasible and promising option for patients suffering from gastric cancer in remnant stomach, with advantages of being a less invasive procedure and having a faster recovery time.

\section{Consent}

Written informed consents were obtained from the patients for the publication of this case report and any accompanying images.

\section{Abbreviations}

LTGIE: Laparoscopic total gastrectomy with intracorporeal

esophagojejunostomy; LAG: Laparoscopic-assisted gastrectomy.
Competing interests

The authors declare that they have no competing interests.

\section{Authors' contributions}

YPM, XWX and KC performed the operation. JQC, DW and YCZ collected case data. Pan $Y$ wrote the manuscript. YPM proofread and revised the manuscript. All authors approved the version to be published.

\section{Acknowledgements}

This work was supported by Zhejiang Key Subject of Medical Science Foundation (grant number: 11-CX-21).

Received: 1 May 2014 Accepted: 20 October 2014

Published: 13 November 2014

\section{References}

1. Japanese Gastric Cancer Association: Japanese classification of gastric carcinoma: 3rd English edition. Gastric Cancer 2011, 14:101-112.

2. Chen K, Xu X, Mou Y, Pan Y, Zhang R, Zhou Y, Wu D, Huang C: Totally laparoscopic distal gastrectomy with D2 lymphadenectomy and Billroth II gastrojejunostomy for gastric cancer: short- and medium-term results of 139 consecutive cases from a single institution. Int J Med Sci 2013, 10:1462-1470.

3. Zhang RC, Yan JF, Xu XW, Chen K, Ajoodhea H, Mou YP: Laparoscopic vs open distal pancreatectomy for solid pseudopapillary tumor of the pancreas. World J Gastroenterol 2013, 19:6272-6277.

4. Xu X, Chen K, Zhou W, Zhang R, Wang J, Wu D, Mou Y: Laparoscopic transgastric resection of gastric submucosal tumors located near the esophagogastric junction. J Gastrointest Surg 2013, 17:1570-1575.

5. Wang W, Chen K, Xu XW, Pan Y, Mou YP: Case-matched comparison of laparoscopy-assisted and open distal gastrectomy for gastric cancer. World J Gastroenterol 2013, 19:3672-3677.

6. Xu XW, Li RH, Zhou W, Wang J, Zhang RC, Chen K, Mou YP: Laparoscopic resection of synchronous intraductal papillary mucinous neoplasms: a case report. World J Gastroenterol 2012, 18:6510-6514.

7. Caygill CP, Hill MJ, Hall CN, Kirkham JS, Northfield TC: Increased risk of cancer at multiple sites after gastric surgery for peptic ulcer. Gut 1987, 28:924-928.

8. Komatsu S, Ichikawa D, Okamoto K, Ikoma D, Tsujiura M, Nishimura Y, Murayama Y, Shiozaki A, Ikoma H, Kuriu Y, Nakanishi M, Fujiwara H, Ochiai T, Kokuba Y, Otsuji E: Progression of remnant gastric cancer is associated with duration of follow-up following distal gastrectomy. World J Gastroenterol 2012, 18:2832-2836.

9. Fukuhara K, Osugi H, Takada N, Takemura M, Ohmoto Y, Kinoshita H: Quantitative determinations of duodenogastric reflux, prevalence of Helicobacter pylori infection, and concentrations of interleukin-8. World J Surg 2003, 27:567-570.

10. Lorusso D, Linsalata M, Pezzolla F, Berloco P, Osella AR, Guerra V, Di Leo A, Demma I: Duodenogastric reflux and gastric mucosal polyamines in the non-operated stomach and in the gastric remnant after Billroth II gastric resection. A role in gastric carcinogenesis? Anticancer Res 2000, 20:2197-2201.

11. Newman E, Brennan MF, Hochwald SN, Harrison LE, Karpeh MS Jr: Gastric remnant carcinoma: just another proximal gastric cancer or a unique entity? Am J Surg 1997, 173:292-297.

12. Viste A, Eide GE, Glattre E, Soreide O: Cancer of the gastric stump: analyses of 819 patients and comparison with other stomach cancer patients. World J Surg 1986, 10:454-461.

13. Russell MC, Mansfield PF: Surgical approaches to gastric cancer. J Surg Oncol 2013, 107:250-258.

14. Chen K, Xu XW, Zhang RC, Pan Y, Wu D, Mou YP: Systematic review and meta-analysis of laparoscopy-assisted and open total gastrectomy for gastric cancer. World J Gastroenterol 2013, 19:5365-5376.

15. Heniford BT, Park A, Ramshaw BJ, Voeller G: Laparoscopic ventral and incisional hernia repair in 407 patients. J Am Coll Surg 2000, 190:645-650.

16. Li MZ, Lian L, Xiao LB, Wu WH, He YL, Song XM: Laparoscopic versus open adhesiolysis in patients with adhesive small bowel obstruction: a systematic review and meta-analysis. Am J Surg 2012, 204:779-786.

17. Yamada H, Kojima K, Yamashita T, Kawano T, Sugihara K, Nihei Z: Laparoscopy-assisted resection of gastric remnant cancer. Surg LaparosC Endosc Percutan Tech 2005, 15:226-229. 
18. Qian F, Yu PW, Hao YX, Sun G, Tang B, Shi Y, Zhao YL, Lan YZ, Luo HX, Mo A: Laparoscopy-assisted resection for gastric stump cancer and gastric stump recurrent cancer: a report of 15 cases. Surg Endosc 2010, 24:3205-3209.

19. Cho HJ, Kim W, Hur H, Jeon HM: Laparoscopy-assisted completion total gastrectomy for gastric cancer in remnant stomach: report of 2 cases. Surg Laparosc Endosc Percutan Tech 2009, 19:e57-e60.

20. Kwon IG, Cho I, Guner A, Choi YY, Shin HB, Kim HI, An JY, Cheong JH, Noh SH, Hyung WJ: Minimally invasive surgery for remnant gastric cancer: a comparison with open surgery. Surg Endosc 2014, 28:2452-2458.

21. Ikeda O, Sakaguchi Y, Aoki Y, Harimoto N, Taomoto J, Masuda T, Ohga T, Adachi E, Toh Y, Okamura T, Baba H: Advantages of totally laparoscopic distal gastrectomy over laparoscopically assisted distal gastrectomy for gastric cancer. Surg Endosc 2009, 23:2374-2379.

22. Song KY, Park CH, Kang HC, Kim JJ, Park SM, Jun KH, Chin HM, Hur H: Is totally laparoscopic gastrectomy less invasive than laparoscopy-assisted gastrectomy?: a prospective, multicenter study. J Gastrointest Surg 2008, 12:1015-1021.

23. Kim MG, Kim KC, Kim BS, Kim TH, Kim HS, Yook JH, Kim BS: A totally laparoscopic distal gastrectomy can be an effective way of performing laparoscopic gastrectomy in obese patients (body mass index $>/=30$ ). World J Surg 2011, 35:1327-1332.

24. Kim HS, Kim BS, Lee IS, Lee S, Yook JH, Kim BS: Laparoscopic gastrectomy in patients with previous gastrectomy for gastric cancer: a report of 17 cases. Surg Laparosc Endosc Percutan Tech 2014, 24:177-182.

25. Jeong O, Park YK: Intracorporeal circular stapling esophagojejunostomy using the transorally inserted anvil (OrVil) after laparoscopic total gastrectomy. Surg Endosc 2009, 23:2624-2630.

26. Ziqiang W, ZhiMin C, Jun C, Xiao L, Huaxing L, PeiWu Y: A modified method of laparoscopic side-to-side esophagojejunal anastomosis: report of 14 cases. Surg Endosc 2008, 22:2091-2094.

doi:10.1186/1477-7819-12-342

Cite this article as: Pan et al:: Three cases of laparoscopic total gastrectomy with intracorporeal esophagojejunostomy for gastric cancer in remnant stomach. World Journal of Surgical Oncology 2014 12:342.

\section{Submit your next manuscript to BioMed Central and take full advantage of:}

- Convenient online submission

- Thorough peer review

- No space constraints or color figure charges

- Immediate publication on acceptance

- Inclusion in PubMed, CAS, Scopus and Google Scholar

- Research which is freely available for redistribution 